Classification

Physics Abstracts

03.20

\title{
Mechanics of cycling
}

\author{
J.-P. Mariot \\ Département Génie Mécanique, Institut Universitaire de Technologie, 72017 Le Mans Cedex, France
}

(Reçu le 10 mai 1983, révisé le 23 novembre, accepté le 5 janvier 1984)

\begin{abstract}
Résumé. - Cette analyse mécanique de la bicyclette tient compte des forces de frottements des pneus sur le sol, de la traînée aérodynamique de l'air, de la pente de la route et du vent. L'étude du mouvement est décrite lorsqu'un couple moyen constant est appliqué à la roue arrière. Pour un cycliste de $72 \mathrm{~kg}$ et une bicyclette de $10 \mathrm{~kg}$, des abaques à points alignés illustrent le mouvement à vitesse constante.
\end{abstract}

\begin{abstract}
This mechanical analysis of cycling includes frictional forces between the tires and the ground, and the influence of the air drag force. The road gradient and the wind are taken into account as well. The movement is studied when an average constant torque is applied on the rear wheel. For a $72 \mathrm{~kg}$ cyclist riding a $10 \mathrm{~kg}$ racing bicycle, aligned charts are given to illustrate the constant speed movement.
\end{abstract}

\section{Introduction.}

Since its invention, a little more than a century ago, the bicycle has been used everywhere in the world and several million are built every year. It has evolved little over the years, as its original shape was both simple and functionally sound. The use of pneumatic tires that permitted improvement in both rolling performance and comfort, then the invention of the gearchange thanks to which a cyclist now can adapt his effort to such difficulties as the wind or hill climbing, were important stages in its development. Recently, wind-tunnel experiments have been carried out by Shimano in Japan and Gitane in France to diminish the influence of air friction. Through this development can be seen the fundamental elements to take into account when designing a bicycle : rolling resistance (solid friction) and air resistance (fluid friction), as well as the inertia of the various parts. It should be added, though, that mechanical losses due to the ball bearings are now negligible considering the excellence of modern products.

The invention of the bicycle is probably as important as that of the wheel (a little over 5000 years ago) because a cyclist requires 5 times less power [1] than a walker. It seems, considering today's energy problems as well as ecological preoccupations, that the bicycle has a promising future. It is nonpollutant and for a $6 \mathrm{~m} / \mathrm{s}$ speed on a level road it requires only a $100 \mathrm{~W}$ power, i.e. the equivalent of the power radiated by the sun over a one square meter portion of our planet.
But what are the laws that govern the working of a bicycle ? The laws of classical mechanics of course, and they are older than the bicycle itself. Unfortunately, from the beginning of mechanical analysis, this machine has defied scientific logic : to this day, its stability has not been thoroughly explained [2-5].

From a mechanical model we shall try to find out the relations among power, effort and speed with the following parameters in mind : rolling resistance, air resistance, the cyclist's weight and that of the machine, the speed of the wind and the gradient of the road; and we shall compare the relative influence of these various parameters thanks to quantitative considerations. This is the recommended procedure when designing a bicycle.

\section{Model.}

The cycle-cyclist set can be considered to be composed of three solids (1), (2) and (3) as shown in figure 1 :

(1) is the front wheel of mass $m_{1}$ and moment of inertia $I_{1}$ about $O_{1}$;

(2) is the rear wheel of mass $m_{2}$ and moment of inertia $I_{2}$ about $\mathrm{O}_{2}$;

(3) is the cyclist-frame set of mass $m_{3}$.

The total mass of the cycle-cyclist set is thus found to be $m=\sum_{i=1}^{3} m_{i}$. 


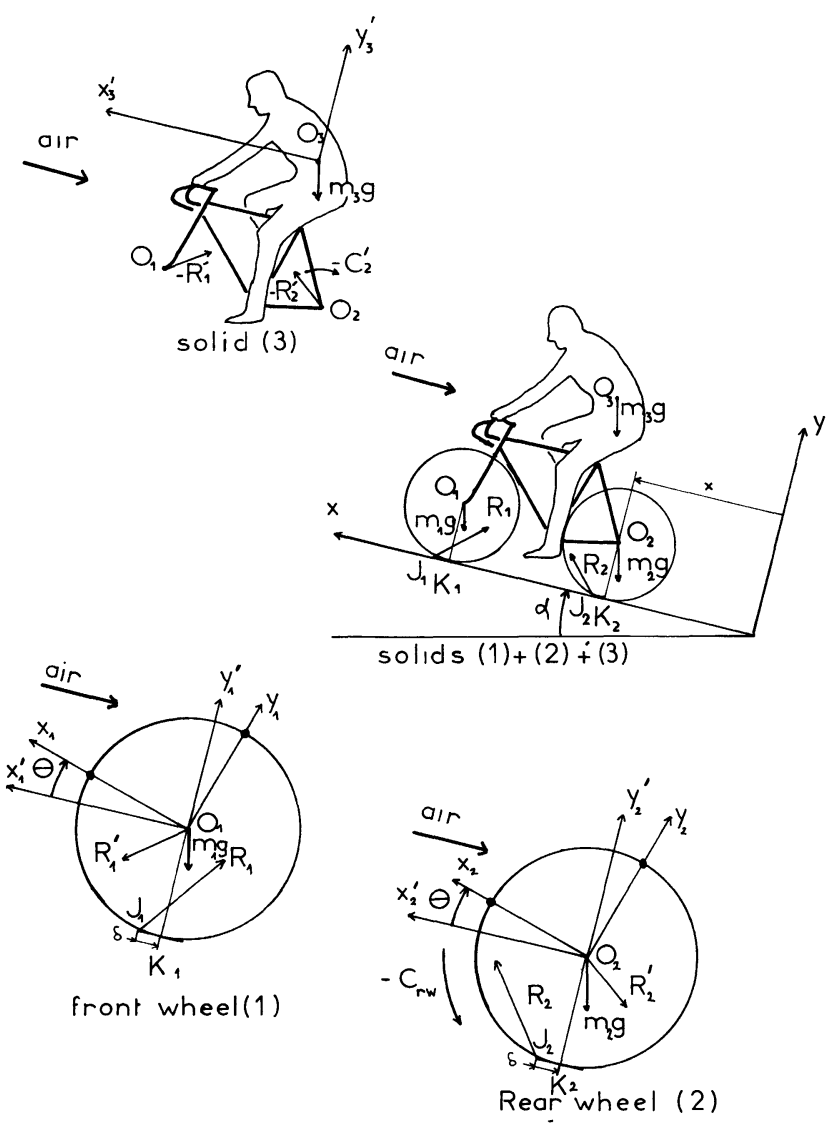

Fig. 1. - External actions on solids (1), (2), (3) and $(1)+(2)+(3)$. Air action is just represented by an arrow. Ground actions are represented by forces $R_{1}$ and $R_{2}$ applied at $J_{1}$ and $J_{2}$.

The following hypotheses are considered in this paper :

a) The movement is such that all applied forces lie in the vertical plane and all applied torques are perpendicular to this plane.

b) The motion equation will be set thanks to a) but solved for a mean constant torque applied to the rear wheel.

There are two variables for the movement : the variable of translation $x$ and the variable of rotation $\theta$ that depends on $x$ in the case when there is no slipping of the wheels on the ground. Such a slipping will not very often occur for cyclists anyhow.

The frame of reference $(g)=(\mathrm{O} x y z)$ with unit vectors $\mathbf{i}, \mathbf{j}, \mathbf{k}$ is a galilean frame of reference.

The frames $\left(\mathrm{O}_{i}, x_{i}^{\prime}, y_{i}^{\prime}, z\right)(i=1,3)$ are barycentric frames for solids (1), (2) and (3).

The frames $\left(\mathrm{O}_{i}, x_{i}, y_{i}, z\right)(i=1,2)$ are the frames fixed in solids (1) and (2).

The variable can now be represented by $\left(\mathrm{OO}_{2}\right)_{x}=x$ and the $\theta$ variable by $\theta=\left(\mathbf{O}_{i} \mathbf{x}_{i}^{\prime}, \mathbf{O}_{i} \mathbf{x}_{i}\right)$ for both wheels (1) and (2), assuming that the two wheels have the same radius (see Fig. 1) $(r=0.342 \mathrm{~m})$.

\section{Motion study.}

It is known from mechanics $[6,7]$ that a mechanical action on a solid (S) can be represented by a system of forces which can be reduced to a "torsor", or wrench [8].

The torsor of mechanical actions $\left\{\mathbf{F}_{\mathrm{S}}\right\}_{\mathrm{M}}$ is defined by $\left\{\begin{array}{c}\mathbf{R} \\ \mathbf{M}_{\mathbf{M}}\end{array}\right\}$ where the (g) letter is standing for " galilean $", \mathbf{R}$ is the vector sum of forces applied to the solid, $\mathbf{M}_{\mathbf{M}}$ is the total moment of forces with respect to $M$. If this mechanical action is calculated about $\mathbf{P}$ instead of $\mathbf{M}$, we have :

$$
\left\{\mathbf{F}_{\mathrm{S}}^{\mathbf{g}}\right\}_{\mathbf{P}}=\left\{\begin{array}{c}
\mathbf{R} \\
\mathbf{M}_{\mathbf{P}}
\end{array}\right\}=\left\{\begin{array}{c}
\mathbf{R} \\
\mathbf{M}_{\mathbf{M}}+\mathbf{P M} \times \mathbf{R}
\end{array}\right\} .
$$

Similarly it is possible to define the following three torsors :

a) The kinematic torsor $\left\{\mathbf{V}_{\mathrm{S}}^{\mathrm{g}}\right\}_{\mathrm{G}}=\left\{\begin{array}{c}\boldsymbol{\omega}_{\mathrm{S}}^{\mathrm{g}} \\ \mathbf{v}_{\mathrm{G}}^{\mathrm{g}}\end{array}\right\}$ where $\omega_{s}^{g}$ is the galilean instantaneous angular rotation and $\mathbf{v}_{\mathrm{G}}^{\mathbf{g}}$ is the galilean velocity of the centre of mass $\mathbf{G}$. If this torsor is calculated about $P$ we have

$$
\left\{\mathbf{V}_{\mathbf{S}}^{\mathrm{g}}\right\}_{\mathbf{P}}=\left\{\begin{array}{c}
\omega_{S}^{\mathrm{g}} \\
\mathbf{v}_{\mathbf{P}}^{\mathrm{g}}
\end{array}\right\}=\left\{\begin{array}{c}
\omega_{\mathrm{S}}^{\mathrm{g}} \\
\mathbf{v}_{\mathbf{G}}^{\mathrm{g}}+\mathbf{P G} \times \boldsymbol{\omega}_{\mathrm{S}}^{\mathrm{g}}
\end{array}\right\} .
$$

b) The kinetic torsor $\left\{\mathbf{P}_{\mathrm{S}}^{\mathrm{g}}\right\}_{\mathrm{G}}=\left\{\begin{array}{c}m v_{\mathrm{G}}^{\mathrm{g}} \\ I_{\mathrm{G}} \omega_{\mathrm{S}}^{\mathrm{g}}\end{array}\right\}$ where $m v_{G}^{g}$ is the momentum of the solid (S) i.e. the product of the mass $m$ of the solid (S) by $\mathbf{v}_{G}^{g}$ and $I_{G}$ is the moment of inertia of the solid about the axis $\mathrm{G} z$. (This applies if all forces lie in the $x y$ plane (see section 2).)

c) The dynamic torsor $\left\{\mathbf{D}_{\mathrm{S}}^{\mathrm{g}}\right\}_{\mathrm{G}}=\left\{\begin{array}{c}m \mathrm{~J}_{\mathrm{G}}^{\mathrm{g}} \\ I_{\mathrm{G}} \dot{\boldsymbol{\omega}}_{\mathrm{S}}^{\mathrm{g}}\end{array}\right\}$ where $\mathbf{J}_{G}^{g}$ is the galilean acceleration of $G$, and $\dot{\omega}_{S}^{g}$ the derivative with respect to time of $\omega_{\mathrm{S}}^{\mathrm{g}}$.

Then, Newton's second law can be written $[6,7]$ :

$$
\left\{\mathbf{F}_{\mathrm{S}}^{\mathrm{g}}\right\}_{\mathrm{G}}=\left\{\mathbf{D}_{\mathrm{S}}^{\mathrm{g}}\right\}_{\mathrm{G}}
$$

leading to 6 scalar equations. For our present study where the only parameter is $x\left({ }^{1}\right)$, it is easier to use the energy-power theorem $[6,7]$ :

$$
P^{\mathrm{g}}\left\{\mathbf{F}_{\mathrm{S}}^{\mathrm{g}}\right\}=\frac{\mathrm{d}}{\mathrm{d} t} E_{\mathrm{C}(\mathbf{S})}^{\mathrm{g}}
$$

$P^{\mathrm{g}}$ is the galilean power of mechanical actions applied to the solid (S) and $E_{\mathrm{C}(\mathrm{S})}^{\mathrm{g}}$ is the galilean kinetic energy of (S).

Equation (b) is a scalar equation. It is then easier to handle than (a) which is a torsor equation i.e. 6 scalar equations but gives less information especially

( $\left.{ }^{1}\right) \theta$ is a function of $x$ (cf. 3.2). 
for calculation of unknown external actions applied to $(\mathrm{S})$.

The galilean power $[6,7]$ of mechanical actions is :

$$
P^{g}\left\{\mathbf{F}_{\mathrm{S}}^{\mathrm{g}}\right\}=\left\{\mathbf{F}_{\mathrm{S}}^{\mathrm{g}}\right\}_{\mathrm{G}} *\left\{\mathbf{V}_{\mathrm{S}}^{\mathrm{g}}\right\}_{\mathrm{G}}=\mathbf{R} \cdot \mathbf{v}_{\mathrm{G}}^{\mathrm{g}}+\mathbf{M}_{\mathrm{G}} \cdot \boldsymbol{\omega}_{\mathrm{S}}^{\mathrm{g}}
$$

where the star $(*)$ is the product of the two torsors and the point (.) is the scalar product; obviously the star product is independent of the point where it is calculated. The reader may verify this assertion by calculating $\mathbf{R} . \mathbf{V}_{\mathrm{P}}^{\mathrm{g}}+\mathbf{M}_{\mathrm{P}} \cdot \boldsymbol{\omega}_{\mathrm{S}}^{\mathrm{g}}$ where $\mathbf{P}$ is an arbitrary point.

The galilean kinetic energy $[6,7]$

$E_{\mathrm{C}}^{\mathrm{g}}(\mathrm{S})=\frac{1}{2}\left\{\mathbf{V}_{\mathrm{S}}^{\mathrm{g}}\right\}_{\mathrm{G}} *\left\{\mathbf{P}_{\mathrm{S}}^{\mathrm{g}}\right\}_{\mathrm{G}}=\frac{1}{2} m \mathbf{v}_{\mathrm{G}}^{\mathrm{g} 2}+\frac{1}{2} I_{\mathrm{G}} \omega_{\mathrm{S}}^{g^{2}}$

is the sum of the translationnal energy $\frac{1}{2} \mathrm{mv}_{\mathrm{G}}^{2 \mathrm{~g}}$ and the rotational energy $\frac{1}{2} I_{\mathrm{G}} \omega_{\mathrm{S}}^{\mathrm{g} 2}$.

3.1 ANALYSIS OF EXTERNAL ACTIONS APPLIED TO THE SOLIDS (1), (2) AND (3). - These actions are (see Fig. 1) :

a) The road action on the wheels:

$$
\left\{\mathbf{G}_{i}^{\mathrm{g}}\right\}_{K_{i}}=\left\{\begin{array}{c}
\mathbf{R}_{i} \\
C_{i} \mathbf{k}
\end{array}\right\}=\left\{\begin{array}{c}
T_{i} \mathbf{i}+N_{i} \mathbf{j} \\
C_{i} \mathbf{k}
\end{array}\right\}
$$

where the lower subscript $i$ is 1 or 2 according to the front or rear wheel, $K_{i}$ is the orthogonal projection of $\mathrm{O}_{i}$ on the road, $T_{i}$ and $N_{i}$ are tangent and normal components of $\mathbf{R}_{i}, C_{i} \mathbf{k}$ is the torque coming from the rolling friction. Let $J_{i}$ be defined by $K_{i} J_{i}=\delta \mathbf{i}$.

Let us calculate $\delta$ so that

$$
\begin{gathered}
\left\{\mathbf{G}_{i}^{\mathbf{g}}\right\}_{J_{i}}=\left\{\begin{array}{c}
\mathbf{R}_{i} \\
\mathbf{O}
\end{array}\right\} \\
\left\{\mathbf{G}_{i}^{\mathrm{g}}\right\}_{J_{i}}=\left\{\begin{array}{c}
\mathbf{R}_{i} \\
C_{i} \mathbf{k}+\mathbf{J}_{i} \mathbf{K}_{i} \times \mathbf{R}_{i}
\end{array}\right\}=\left\{\begin{array}{c}
\mathbf{R}_{i} \\
\left(C_{i}-\delta \mathbf{N}_{i}\right) \mathbf{k}
\end{array}\right\} .
\end{gathered}
$$

Hence $\delta=C_{i} / N_{i}$; because $C_{i}$ and $N_{i}$ are positive, $\delta$ is positive. This shift $\delta$ of the force $\mathbf{R}_{i}$ shows the rolling friction torque and characterizes the rolling friction. Most measurements of this torque give directly $C_{\mathrm{r}}=\delta / r$ which we call the friction rolling coefficient.

b) The weight :

$$
\left\{\mathbf{W}_{i}^{g}\right\}_{O_{i}}=\left\{\begin{array}{c}
m_{i} g \\
0
\end{array}\right\}_{o_{i}}
$$

where $\mathrm{O}_{i}$ is the centre of mass of solids (1), (2) and (3), $m_{i}$ the respective mass, and $g$ the gravity acceleration vector.

c) The air action:

$$
\left\{\mathbf{A}_{i}^{\mathbf{g}}\right\}_{\mathbf{O}_{i}}=\left\{\begin{array}{c}
D r_{i} \mathbf{i} \\
C a_{i} \mathbf{k}
\end{array}\right\}
$$

where $D r_{i}$ is the air drag force and $C a_{i}$ the ventilation torque. d) The actions between solids :

$$
\left\{\mathbf{L}_{i}^{\mathrm{g}}\right\}_{\mathrm{O}_{i}}=\left\{\begin{array}{c}
\mathbf{R}_{i}^{\prime} \\
C_{i}^{\prime} \mathbf{k}
\end{array}\right\}
$$

for $i=1$ it represents action of $(3) \rightarrow(1)$,

for $i=2$ it represents action of $(3) \rightarrow(2)$,

for $i=3$ it represents action of $(1) \rightarrow(3)$,

$$
\text { and }(2) \rightarrow(3) \text {. }
$$

From Newton's third law $\mathbf{L}_{3}^{\mathbf{g}}=-\mathbf{L}_{1}^{\mathbf{g}}-\mathbf{L}_{2}^{\mathbf{g}}$. Moreover $C_{1}^{\prime}=0$. Denoting by $C_{\mathrm{rw}}$ the propulsive torque, applied to the rear wheel through the chain, we have $C_{2}^{\prime}=-C_{\mathrm{rw}}\left(\right.$ we take $\left.C_{\mathrm{rw}}>0\right)$.

\subsection{POWER OF EXTERNAL ACTIONS AND KINETIC ENERGY.} - To calculate $P^{\mathrm{g}}$ and $E_{\mathrm{c}}^{\mathrm{g}}$ we need the 3 kinematic and kinetic torsors (see Eq. (c) and Eq. (d)).

The kinematic torsor $\left\{\mathbf{V}_{i}^{\mathrm{g}}\right\}_{\mathrm{o}_{i}}=\left\{\begin{array}{l}\dot{\theta}_{i} \mathbf{k} \\ \dot{x} \mathbf{i}\end{array}\right\}$ where $\dot{\theta}_{i} \mathbf{k}$ is the galilean angular velocity of solid $(i)$; $\dot{\theta}_{1}=\dot{\theta}_{2}=\dot{\theta}$ because front and rear wheels have the same radius and there is no slipping. $\dot{\theta}_{3}=0$ because solid (3) does not rotate. The galilean velocity of $\mathbf{O}_{i}$ is $\dot{x} \mathbf{i}$.

The kinetic torsor $\left\{\mathbf{P}_{i}^{\mathrm{g}}\right\}_{\mathrm{O}_{i}}=\left\{\begin{array}{c}m_{i} \ddot{x} \mathbf{i} \\ I_{i} \dot{\theta}_{i} \mathbf{k}\end{array}\right\}$ where $I_{i}$ is the moment of inertia about $\mathrm{O}_{i}$.

The rolling without slipping conditions can be derived from the nullity of the instantaneous velocity in $K_{1}\left(\right.$ or $\left.K_{2}\right)$

$$
\left\{\mathbf{V}_{1}^{\mathbf{g}}\right\}_{K_{1}}=\left\{\begin{array}{c}
\dot{\theta} \mathbf{k} \\
\dot{x} \mathbf{i}+\mathbf{K}_{1} \mathbf{O}_{1} \times \dot{\theta} \mathbf{k}
\end{array}\right\}=\left\{\begin{array}{c}
\dot{\theta} \mathbf{k} \\
(\dot{x}+r \dot{\theta}) \mathbf{i}
\end{array}\right\} .
$$

Hence the condition is

$$
\dot{x}+r \dot{\theta}=0 .
$$

In section 3.1 we have calculated

$$
\left\{\mathbf{F}_{i}^{\mathrm{g}}\right\}_{\mathbf{O}_{i}}=\left\{\mathbf{G}_{i}^{\mathrm{g}}\right\}_{\mathrm{O}_{i}}+\left\{\mathbf{W}_{i}^{\mathrm{g}}\right\}_{\mathrm{O}_{i}}+\left\{\mathbf{A}_{i}^{\mathrm{g}}\right\}_{\mathbf{O}_{i}}+\left\{\mathbf{L}_{i}^{\mathrm{g}}\right\}_{\mathbf{O}_{i}}
$$

(it should be noted that $\left\{\mathbf{G}_{3}^{\mathrm{g}}\right\}=0$ ). From equation (c) we have

$$
P^{\mathrm{g}}\left(\sum_{i=1}^{3}\left\{\mathbf{F}_{i}^{\mathrm{g}}\right\}\right)=\sum_{i=1}^{3}\left\{\mathbf{F}_{i}^{\mathrm{g}}\right\}_{\mathrm{O}_{i}^{*}}\left\{\mathbf{V}_{i}^{\mathrm{g}}\right\}_{\mathrm{O}_{i}}
$$

Hence

$$
\begin{aligned}
& P g\left(\sum_{i=1}^{3}\left\{\mathbf{F}_{i}^{\mathrm{g}}\right\}\right)=\underbrace{\left(D r_{1}+D r_{2}+D r_{3}-\frac{C a_{1}+C a_{2}}{r}\right)}_{\text {air action }} \times \\
& \times \underbrace{\dot{m g \dot{x}}\left(C_{\mathrm{r}}+\mathrm{s}\right)}_{\begin{array}{c}
\text { ground }+ \text { gradient } \\
\text { action }
\end{array}}+\underbrace{C_{\mathrm{rw}} \frac{\dot{x}}{r}}_{\begin{array}{c}
\text { propulsive } \\
\text { torque }
\end{array}}
\end{aligned}
$$

where $s$ is the road gradient. 
The fluid term is indeed negative for $D r_{i}$ is negative and $C a_{i}$ is positive. Usually one sets :

$$
D r_{1}+D r_{2}+D r_{3}-\frac{C a_{1}+C a_{2}}{r}=-\frac{1}{2} \rho S C_{\mathrm{x}} \dot{x}^{2}
$$

where $\rho$ is the air volumic mass, $S$ the frontal area of the bicycle-cyclist solid, $C_{\mathrm{x}}$ the drag coefficient and $\dot{x}^{2}$ the square of the velocity.

$$
P_{\mathrm{rw}}=\frac{C_{\mathrm{rw}}}{r} \dot{x}
$$

is the power applied to the rear wheel through the chain. Equation (2) becomes

$$
\begin{aligned}
P^{\mathrm{g}}\left(\sum_{i=1}^{3}\left\{F_{i}^{\mathrm{g}}\right\}\right)=-\frac{1}{2} \rho S C_{\mathrm{x}} \dot{x}^{3}- & \\
& \quad-m g \dot{x}\left(C_{\mathrm{r}}+s\right)+P_{\mathrm{rw}} .
\end{aligned}
$$

From equation (d), we get the galilean kinetic energy

$$
\begin{aligned}
E_{\mathrm{c}}^{\mathrm{g}}((1)+(2)+(3))=E_{\mathrm{c}}^{\mathrm{g}}(1) & +E_{\mathrm{c}}^{\mathrm{g}}(2)+E_{\mathrm{c}}^{\mathrm{g}}(3)= \\
= & \frac{1}{2} \sum_{i=1}^{3}\left\{\mathbf{V}_{i}^{\mathrm{g}}\right\}_{\mathbf{O}_{i}} *\left\{\mathbf{P}_{i}^{\mathrm{g}}\right\}_{\mathrm{O}_{i}}
\end{aligned}
$$

Hence

$$
E_{\mathrm{c}}^{\mathrm{g}}((1)+(2)+(3))=\frac{1}{2} m \dot{x}^{2}+\frac{1}{2}\left(I_{1}+I_{2}\right) \dot{\theta}^{2} .
$$

With the no slipping condition, equation (5) becomes :

$$
E_{\mathrm{c}}^{\mathrm{g}}((1)+(2)+(3))=\frac{1}{2} m_{\mathrm{eq}} \dot{x}^{2}
$$

where $m_{\mathrm{eq}}=m+\frac{I_{1}+I_{2}}{r^{2}}$ is called the equivalent mass.

3.3 THE MOtion EQUATION. - According to equa(b) and from equations (6) and (5) we obtain the motion equation :

$m_{\mathrm{eq}} \ddot{x}+\frac{1}{2} \rho S C_{\mathrm{x}} \dot{x}^{2}+m g\left(C_{\mathrm{r}}+s\right)-\frac{C_{\mathrm{rw}}}{r}=0$

$\ddot{x}$ is the acceleration of the cyclist. The above equation is in agreement with reference [9] where only the propulsive torque was taken into account $\left(\rho=C_{\mathrm{r}}=\right.$ $s=0$ ), and represents the linear movement of a solid of mass $m_{\mathrm{eq}}\left(m_{\mathrm{eq}}\right.$ is close to $\left.m\right)$ with a velocity $\dot{x}$ under the effect of a force $C_{\mathrm{rw}} / r$ on a gradient $s$ with fluid and solid friction. This model can be easily adapted to a runner [10] in which case fluid friction is about the same magnitude, considering the similar speeds reached for sprints, but solid friction is more important.
3.4 DisCUSSING THE MOTION EQUATION IN TERMS OF THE VARIOUS PARAMETERS.

3.4.1 Equivalent mass. - It has just been seen that $m_{\mathrm{eq}}=m+\frac{I_{1}+I_{2}}{r^{2}}$.

Typically $I_{1}$ and $I_{2}$ for light aluminium wheels fitted with $250 \mathrm{~g}$ tubular tires are approximately $0.1 \mathrm{kgm}^{2}$ leading to an equivalent mass of $83.7 \mathrm{~kg}$ $(82+1.7)$. Under such conditions saving $100 \mathrm{~g}$ on each tire gives $\frac{\Delta m_{\mathrm{eq}}}{m_{\mathrm{eq}}}=\frac{0.4}{83.7}=5 \times 10^{-3}$ and $\frac{\Delta m}{m}=$ $2.5 \times 10^{-3}$.

This mass effect on velocity will be examined in section 4.2. Mass mainly matters in terms of acceleration $\left(m_{\mathrm{eq}} \ddot{x}\right)$ and road gradients (mgs) (see Eq. (7)). In bicycle racing for instance, where accelerations are frequent, the lighter the bicycle, the better - so long as the rigidity of the frame is preserved. If the bicycle lacks rigidity, the mechanical efficiency is impaired.

3.4.2 Air influence. - The air volumic mass depends on temperature and pressure mainly. It decreases slightly when humidity increases. Under usual circumstances

$\rho=1.205 \mathrm{kgm}^{-3}$ for $T=294 \mathrm{~K}$ and $P=10^{5} \mathrm{~Pa}$

The $C_{\mathrm{x}}$ factor depends mainly on the cyclist's position. What matters in fact is rather the $S C_{\mathrm{x}}$ factor. Loose clothing such as rain equipment drastically increases this factor; the same applies to a bicycle fitted with front bags. This $S C_{\mathrm{x}}$ factor has been measured experimentally in a wind-tunnel [11] with a $72 \mathrm{~kg}$ cyclist pedaling on a $10 \mathrm{~kg}$ racing bicycle. Figure 2

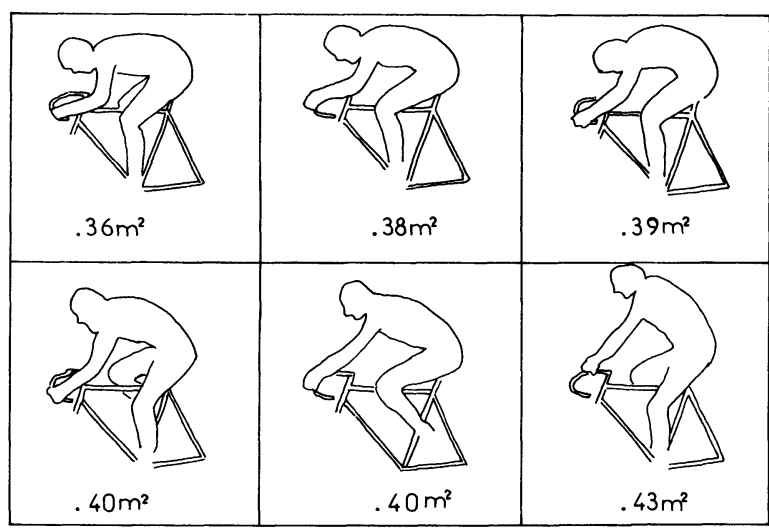

Fig. $2\left(^{*}\right)$. - Various $S C_{\mathrm{x}}$ factors for different cycling positions. These experiments were carried out at «Institut Aérotechnique de St Cyr " (France). A small $S C_{\mathrm{x}}$ is obtained for a very low position of the elbows and the back as flat as possible.

(*) For figures 2, 4, 5, 7 results are given for a $72 \mathrm{~kg}$ cyclist riding a $10 \mathrm{~kg}$ non profiled bicycle. International units are used. Charts have been calculated with a HP 97 calculator. 
shows the results obtained for 6 positions from the touring position $\left(S C_{\mathrm{x}}=0.43 \mathrm{~m}^{2}\right)$ to the crouched racing position $\left(S C_{\mathrm{x}}=0.36 \mathrm{~m}^{2}\right)$. This measured $S C_{\mathrm{x}}$ represents an average; indeed, while pedaling, the cyclist presents a variable area to air depending on whether his feet are in the upper-lower position or median position. Approximately two thirds of energy losses [11] through fluid friction are due to the cyclist himself. Consequently, the profiling of a racing bicycle will bear on only about one third of the remaining fluid friction losses.

The profiling of the bicycle on which B. Hinault (the 1980 world champion) races saves $70 \mathrm{~W}$ [11] at a $13.8 \mathrm{~m} / \mathrm{s}$ velocity compared to a similar but unprofiled bicycle. This includes a significant saving due to elliptic instead of circular spokes, and using 28 spokes rather than the usual 36 for the front wheel. This saving has been obtained through measuring the $D r_{i}$ drag force and the $C a_{i}$ ventilation torque of a wheel put in a wind-tunnel [12]. At $13.8 \mathrm{~m} / \mathrm{s}$ this $70 \mathrm{~W}$ is about one tenth of the total power needed by the cyclist, leading to a $3 \%$ velocity gain $\left(\frac{\Delta P}{P}=3 \frac{\Delta V}{V}\right)$ at $13.8 \mathrm{~m} / \mathrm{s}$. For the same power a $13.8 \mathrm{~m} / \mathrm{s}$ velocity thus becomes $14.2 \mathrm{~m} / \mathrm{s}$ on a profiled bicycle.

For a wind velocity $w$ on the road, $\frac{1}{2} \rho S C_{\mathrm{x}} \dot{x}^{2}$ must be changed to $\frac{1}{2} \rho S C_{\mathrm{x}}(\dot{x}+w)^{2}$ when the wind is parallel to the cyclist's velocity (with a favorable wind $w<0)$. Side wind is rather difficult to consider because one should measure $S C_{\mathrm{x} \cos \beta}, \beta$ being the angle between the cyclist's velocity and the wind velocity [13].

3.4.3 Rolling resistance. - The $C_{\mathrm{r}}$ factor depends on the road surface [1] and the tires. For excellent tubular tires [11], it can be lowered to 0.008 ; and, under normal circumstances, it is found to be independent of the weight and the speed.

3.4.4 Propulsive torque. - The cyclist's power is conveyed through the pedals. Figure $3 a$ shows the normal $\left(F_{\mathrm{N}}\right)$ and tangent $\left(F_{\mathrm{T}}\right)$ components of the force $F$ applied by the cyclist on the pedal. The $C_{\mathrm{rw}}$ torque is only produced by the $F_{\mathrm{T}}$ component as the $F_{\mathrm{N}}$ normal component has a zero power. Figure $3 b$ shows the diagram of the tangent and normal components which have been obtained using dynamometric gauges fitted between the cyclist's feet and the pedals [14]. From the $\left(F_{\mathrm{T}}\right)$ diagram the relation between the maximum force $\left(F_{\max }\right)$ and the mean force $\left(F_{m}\right)$ is found to be $1.7 F_{\mathrm{m}}\left({ }^{2}\right)$, rather close to 1.57 corresponding to a sinusoidal variation of the $F_{\mathrm{T}}$ force. The mean torque produced by the cyclist is therefore $l F_{\mathrm{m}}$ where $l$ is the crank length. The corresponding power is $-l F_{\mathrm{m}} \dot{\gamma}$ (see Eq. (c)) where $\dot{\gamma} \mathbf{k}$ is the angular rotation of the crank-wheel ( $\dot{\gamma}$ as $\dot{\theta}$ is negative). Let $\eta$ be the efficiency of the chain, the power $P_{\mathrm{rw}}$ transmitted

$\left.{ }^{2}\right)$ This holds for $0<\gamma<180^{\circ}$ for one pedal.

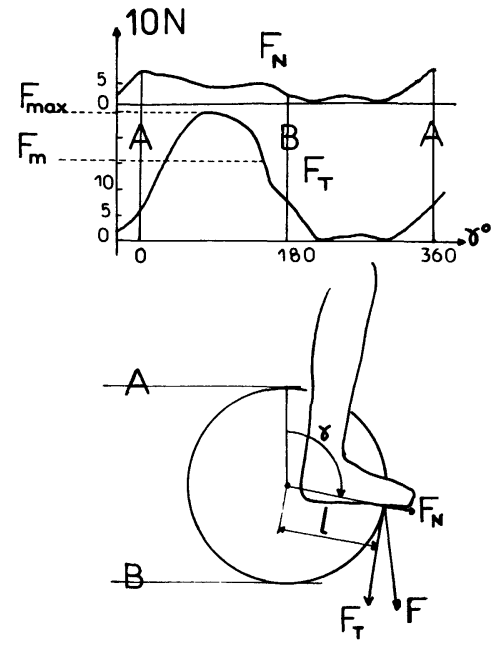

Fig. 3. - Tangent $F_{\mathrm{T}}$ and normal $F_{\mathrm{N}}$ force according to the angular position of the crank-wheel. The cyclist's feet were firmly strapped to the pedals fitted with toeclips.

to the rear wheel is thus found to be $-\eta l F_{\mathrm{m}} \dot{\gamma}$. If $T_{\mathrm{c}}$ and $T_{\mathrm{r}}$ denote the number of teeth of the crank-wheel and of the rear wheel, we have $\dot{\gamma}=\dot{\theta} \frac{T_{\mathrm{r}}}{T_{\mathrm{c}}}$.

The gear $d$ is the distance covered by the cyclist for one crank-wheel revolution. Hence

$$
d=2 \pi r \frac{T_{\mathrm{c}}}{T_{\mathrm{r}}}
$$

From (Eq. (3)) where $P_{\mathrm{rw}}=C_{\mathrm{rw}} \frac{\dot{x}}{r}$ and equation (1) we obtain $C_{\mathrm{rw}}=\eta l F_{\mathrm{m}} \frac{T_{\mathrm{r}}}{T_{\mathrm{c}}}$. Considering a sinusoidal variation of the force $F_{\mathrm{T}}$ applied on the pedal i.e. $F_{\max }=\frac{\pi}{2} F_{\mathrm{m}}$ and using equation (7) we have

$$
C_{\mathrm{rw}}=4 \eta l r \frac{F_{\mathrm{max}}}{d}
$$

3.4.5 Comparison of the influence of the various parameters. - Figure 4 shows the variation of speed depending on the various losses. Rolling friction losses, linearly depending on velocity (dotted lines in Fig. 4), are slight and correspond approximately to losses in a $1 \%$ uphill gradient. $C_{\mathrm{r}}$ and $s$ have the same bearing upon the motion equation.

On a level road (with no wind) losses due to rolling friction and air friction are equal when speed is about $6 \mathrm{~m} / \mathrm{s}$. This corresponds to a $100 \mathrm{~W}$ cyclist's power. When going faster fluid losses go up and at a $10 \mathrm{~m} / \mathrm{s}$ speed they are four times more important than solid losses.

Although linear, losses due to uphill gradients matter a great deal considering that at a $10 \mathrm{~m} / \mathrm{s}$ speed, fluid losses are equal to gradient losses for a $3 \%$ 


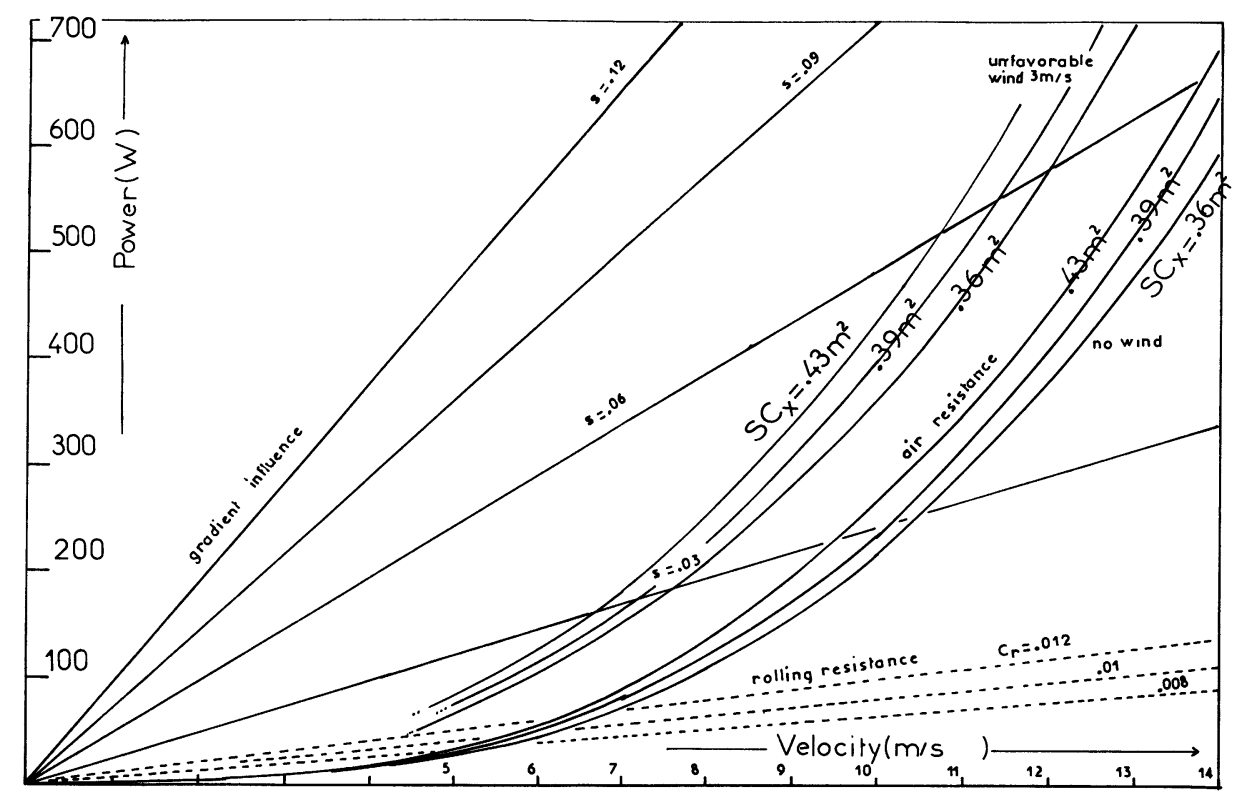

Fig. 4(*). - Comparison of the influence of air and wind resistance, road gradient and rolling resistance. Power of the various losses is drawn versus speed.

gradient. For the avefage cyclist climbing an uphill gradient of $5 \%$ or more, gradient losses are much more significant than fluid friction. Reducing the weight of the cyclist and his machine will increase efficiency in the gradient losses case.

For a given uphill gradient, an unfavorable wind $(w>0)$ causes the speed to decrease drastically as shown on figure 4 for a $3 \mathrm{~m} / \mathrm{s}$ wind speed.

Wind and uphill gradients are thus meaningful elements when cycling.

It is easy to understand that the use of such diagrams is a complicated matter. So we have appended aligned charts which are easier to handle. Charts [15] are used for the graphic resolution of algebraic equations. Let $f(x, y, z)=0$ be such an equation. The problem is to calculate $z$ if $x$ and $y$ are known. This calculation is graphically made with a ruler in the case of aligned charts. For example figure 7 shows the relations among the power applied to rear wheel $P_{\text {rw }}$ the speed of the cyclist $V$, and the road gradient $s$ in \%. If $V=5.45 \mathrm{~m} / \mathrm{s}$ for a level road, one finds $P_{\mathrm{rw}}=77 \mathrm{~W}$ (straight line with circles on figure 7).

\section{Solving the motion equation.}

In keeping with section 3.4.2 we adopted an averaged value for the $S C_{\mathrm{x}}$ factor; we shall also average $C_{\mathrm{rw}}$ on a crank-gear revolution (lasting usually between $0.5 \mathrm{~s}$ and $2 \mathrm{~s}$ ); and we shall assume moreover that this $C_{\mathrm{rw}}$ value is time independent. Two cases should be taken into account depending on whether the speed $(\dot{x})$ is variable or not.
4.1 Time-DEPENDENT SOlUtion (VARIABLE SPEED). Setting

$$
A=\frac{1}{2} \frac{\rho S C_{\mathrm{x}}}{m_{\mathrm{eq}}} \text { and } B=\frac{1}{m_{\mathrm{eq}}}\left(\frac{C_{\mathrm{rw}}}{r}-m g\left(C_{\mathrm{r}}+s\right)\right)
$$

the motion equation (Eq. (7)) becomes

$$
\ddot{x}+A \dot{x}^{2}-B=0 .
$$

Equation (10) may be reduced to a simple linear differential equation when setting $V=\dot{x}$ : the solution of this equation is : $V=\sqrt{\frac{B}{A}} \tanh \sqrt{A B} t$ taking $x=\dot{x}=0$ as initial conditions. Figure 5 shows how

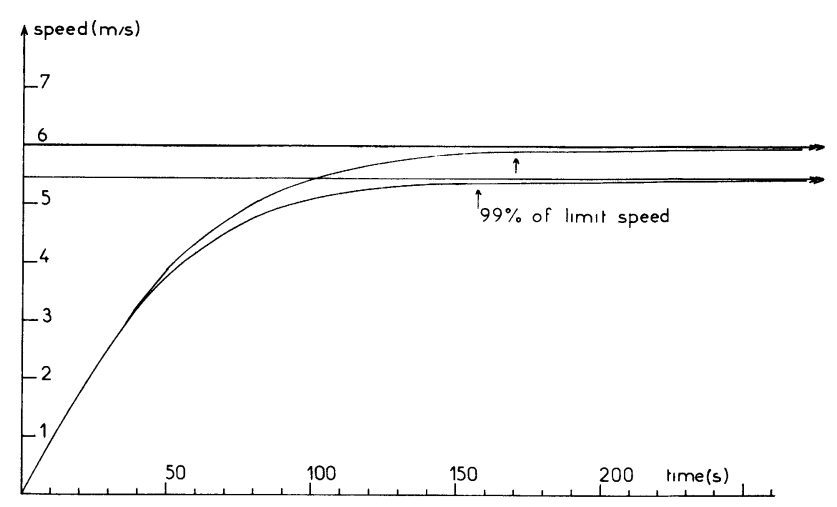

Fig. 5(*). - Speed variation on level road for a $150 \mathrm{~N}$ maximum force applied on the pedal and a $7 \mathrm{~m}$ gear for two $S C_{\mathrm{x}}$ values. The chain efficiency $\eta$ is 0.97 . 
the speed varies with time on a level road for two $S C_{\mathrm{x}}$ factors and $F_{\max }=150 \mathrm{~N}$. As $t$ goes to infinity $V$ will reach $\sqrt{\frac{B}{A}}$ which is the limit speed (see next section).

Usually, a cyclist will apply a large torque when starting then will relax his effort; in fact, a cyclist will tend to ride so that his applied power is as steady as possible. In figure 5 where $F_{\max }$ is constant, the applied power, which is $P_{\mathrm{rw}} / \eta$, is increasing with time similarly to speed.

4.2 Velocity eQuation (STEAdy SPEED). - For a steady speed $\ddot{x}=0$, and we can calculate the speed $V$ from the motion equation (Eq. (7)) and equation (9)

$$
V=\sqrt{\frac{B}{A}}=\left[\frac{2}{\rho S C_{\mathrm{x}}}\left(4 \eta l \frac{F_{\max }}{d}-m g\left(C_{\mathrm{r}}+s\right)\right)\right]^{1 / 2} .
$$

For a given cyclist ( $m$ and $S C_{\mathrm{x}}$ fixed) riding a bike with a gear $d$, on a road of gradient $s$ the speed is a function of $F_{\max } / d$.

(The sinusoidal variation of the force is still considered.) This latter equation is not very important for cyclists because the maximum force $F_{\max }$ is not correlated to heart frequency which is one of the fundamental biological parameter in cycling. On the contrary the applied power, $P_{\mathrm{rw}} / \eta$, is directly connected to heart frequency and thus very useful.

From equations (2) and (7)

$$
P_{\mathrm{rw}}=\frac{1}{2} \rho S C_{\mathrm{x}} V^{3}+m g V\left(C_{\mathrm{r}}+s\right) .
$$

With the new parameters $q=-\frac{2 P_{\mathrm{rw}}}{\rho S C_{\mathrm{x}}}$ and

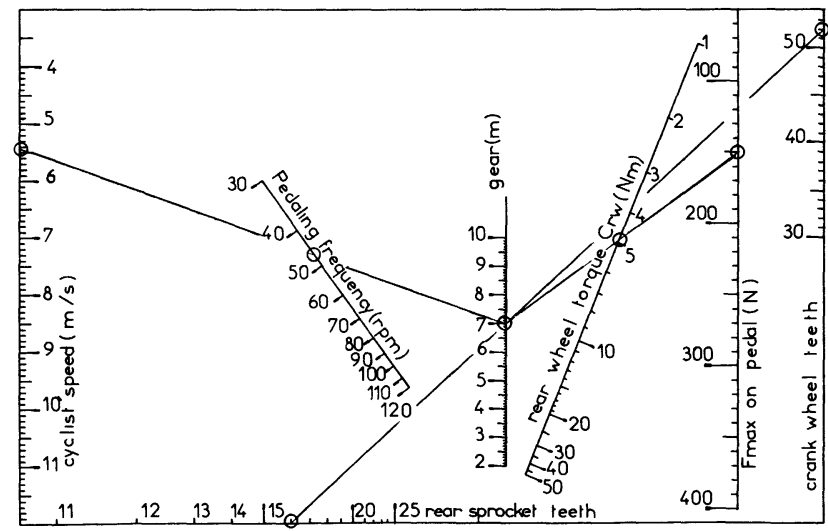

Fig. 6. - Universal charts for a wheel radius of $r=0.342 \mathrm{~m}$ and a crank-wheel length of $l=0.17 \mathrm{~m}$. These charts give the relations among speed, pedaling frequency, gear, number of teeth at rear sprocket and crank-wheel, torque applied to the rear wheel, and maximum force applied on the pedal. $p=\frac{2 m g\left(C_{\mathrm{r}}+s\right)}{\rho S C_{\mathrm{x}}}$, equation (11) becomes

$$
V^{3}+p V+q=0
$$

from which the $\left(P_{\mathrm{r} w}, S, V\right)$ charts are derived (see Fig. 7).

Let us remark that :

a) if $\rho=0$ (no fluid friction) and $s=0$ (level road) for $P_{\mathrm{rw}}=100 \mathrm{~W}$, the speed will be

$$
V=\frac{P_{\mathrm{rw}}}{m g C_{\mathrm{r}}}=15.5 \mathrm{~m} / \mathrm{s} .
$$

How fine it will be to cycle on the moon! Moreover gravity on the moon is $1 / 6$ of earth's gravity.

b) According to section 3.4.1 let us evaluate the weight influence on speed for a $s=5 \%$ uphill gradient. From equation (12) we have

$\frac{\mathrm{d} \dot{x}}{\mathrm{~d} m}=\frac{-g \dot{x}\left(C_{\mathrm{r}}+s\right)}{\frac{3}{2} \rho S C_{\mathrm{x}} \dot{x}^{2}+m g\left(C_{\mathrm{r}}+s\right)}=-0.05 \mathrm{~ms}^{-1} \mathrm{~kg}^{-1}$

$\left(m=82 \mathrm{~kg}, V=10 \mathrm{~m} / \mathrm{s}, S C_{\mathrm{x}}=0.43 \mathrm{~m}^{2}\right)$.

A saving of $200 \mathrm{~g}$ gives $\Delta \dot{x}=0.01 \mathrm{~m} / \mathrm{s}$. The cyclist will catch up one second every $1000 \mathrm{~s}$ which is very little.

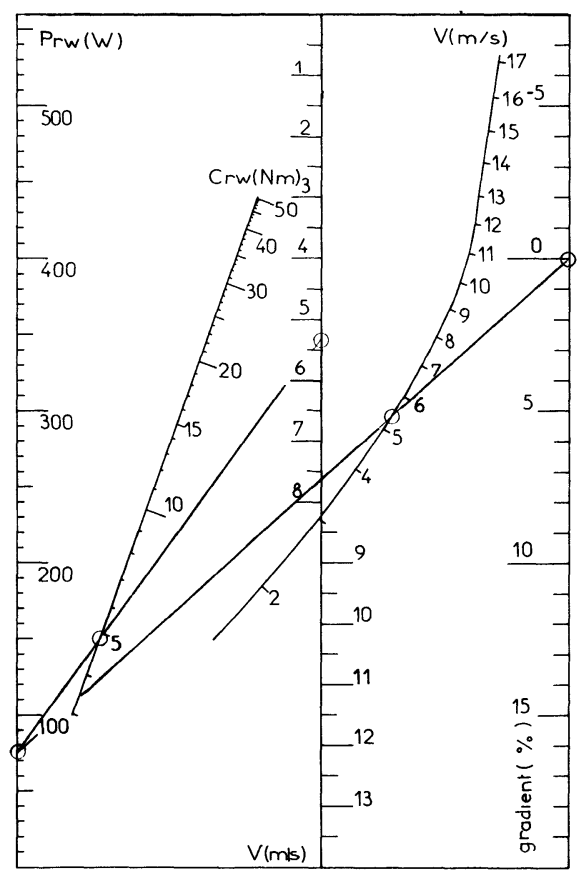

Fig. $7\left(^{*}\right)$. - Charts giving the relations among the power $P_{\mathrm{rw}}$, the speed $V$ and the road gradient $s$. From power and speed, the rear torque $C_{\mathrm{rw}}$ can be computed as well. These charts are valid only for steady speeds and $m=82 \mathrm{~kg}$, $S C_{\mathrm{x}}=0.43 \mathrm{~m}^{2}$ and $C_{\mathrm{r}}=0.008$. 
c) Let us now calculate the $\mathrm{d} \dot{x} / \mathrm{d} S C_{\mathrm{x}}$ value with the same hypotheses as $b$ )

$$
\frac{\mathrm{d} \dot{x}}{\mathrm{~d} S C_{\mathrm{x}}}=\frac{-\frac{1}{2} \rho \dot{x}^{3}}{\frac{3}{2} \rho S C_{\mathrm{x}} \dot{x}^{2}+m g\left(C_{\mathrm{r}}+s\right)}=-5 \mathrm{~m}^{-1} \mathrm{~s}^{-1} \text {. }
$$

Going from $S C_{\mathrm{x}}=0.43 \mathrm{~m}^{2}$ to $S C_{\mathrm{x}}=0.40 \mathrm{~m}^{2}$ will lead to $\Delta \dot{x}=0.15 \mathrm{~m} / \mathrm{s}, 15$ times more than $b$ ). This shows the great importance of the $S C_{\mathrm{x}}$ factor compared to the weight factor.

\section{Conclusion.}

To assess the validity of the model, one should measure a cyclist's power during a definite time span. Such experiments have been carried out individually on professional racing cyclists of the Renault-Gitane team, at the Nantes Medical Centre, by Professor Ginet. The results obtained show that the speed the cyclists reached individually on the road is slightly superior to the one computed from the model, using the power measured in the laboratory. This power is measured on a bicycle similar to the one actually used by the team on the road. This superior result might stem from an inadequate ventilation [1] (as compared to road conditions) in the laboratory. Anyway only continued measurements and field work will make it possible to sharpen this model.

It should be noted that turns have not been considered here. The only influence of turns would be to bring in the centrifugal force (in proportion to $\dot{x}^{2}$ ) $w$ ose $e$ ec is o increase $t$ e tota weig $t$ in motion. For example if the centrifugal force is equal to the total weight (very sharp turns), the apparent weight and the rolling losses will be increased by $41 \%$. Lightweight and profiling are essential aspects. They make it possible to reduce the losses due to uphill gradients and air resistance. If the Belgian champion E. Merckx had ridden a profiled bicycle when setting his world distance record, the gain would have been $3 \%$ in speed. It is thus likely he would have broken the $51 \mathrm{~km}$ barrier within one hour. Accordingly, profiling is more than trifling publicity, but really the outcome of scientific studies in a wind-tunnel. Lately the tricycle " Vector " [16] thoroughly streamlined, and strictly man-powered has sped beyond the $26 \mathrm{~m} / \mathrm{s}$ mark. To achieve this, it was necessary to decrease the $S C_{\mathrm{x}}$ to about $0.1 \mathrm{~m}^{2}$.

Its having three wheels is no obstacle. It has no influence on rolling resistance because the latter losses are equal to product $C_{\mathrm{r}}$ multiplied by weight.

\section{Addenda. Illustration of equations with the aid of charts.}

The linear relation among speed $V$, gear $d$ and pedaling frequency $N$ is

$$
V=\frac{N d}{60} .
$$

a) On figure 6, equations (8), (9), (14) are illustrated for $\eta=0.97, l=0.17 \mathrm{~m}$ and $r=0.342 \mathrm{~m}$. These equations are valid for steady and variable speed.

b) On figure 7, equations (3) and (12) are illustrated for $S C_{\mathrm{x}}=0.43 \mathrm{~m}^{2}, C_{\mathrm{r}}=0.008, m=82 \mathrm{~kg}, \rho=$ $1.205 \mathrm{~kg} \mathrm{~m}^{-3}$. Figure 7 is only useable for steady speed.

\section{Using these charts.}

a) Calculating the power of the cyclist. One only has to measure the pedaling frequency in rpm and the gradient in $\%$. The gear is known from the number of teeth in the front and rear sprockets. The velocity and road gradient make it possible to calculate the $P_{\mathrm{rw}}$ power needed. From this one can obtain $C_{\mathrm{rw}}$ and consequently $F_{\max }$. The example illustrated in figures 6 and 7 is valid for a $7 \mathrm{~m}$ gear ( 52 teeth on the crank-wheel, 16 teeth on the rear sprocket) and a $47 \mathrm{rpm}$ pedaling frequency. This allows $5.45 \mathrm{~m} / \mathrm{s}$ on a level road with a zero wind. The $P_{\text {rw }}$ power comes up to $77 \mathrm{~W}$ which gives a $C_{\mathrm{rw}}$ torque of $4.84 \mathrm{Nm}$ and consequently a maximum force $F_{\max }=150 \mathrm{~N}$ on the pedal.

b) Velocity calculation on hilly roads. Our cyclist now knows his available power, taking into account the duration of his effort. He can therefore compute his corresponding speed for a given road gradient using the $P_{\mathrm{rw}}, V, s$ chart. Knowing his speed he can quickly find out how much time he will need for a iv $\mathbf{n}$

grades up to $8 \%$. If the cyclist applies his brakes, the chart becomes useless as $P_{\mathrm{rw}}$ becomes negative. From his speed, he can pick out his gear. Two options are open to him : either a low pedaling frequency with a strong applied force on the pedal or a higher pedaling frequency leading to a lesser effort. These two options depend mostly on the cyclist's training and constitution. Personal style determines these two elements.

c) It is possible, but not easy, to illustrate equation (11) giving the variation of the steady speed $V$ with respect to $C_{\mathrm{rw}}$ (or $F_{\max }$ ) and the road gradient $s$. If $\mathrm{s}$ and $C_{\mathrm{rw}}$ (or $F_{\max }$ ) are given, $V$ can be calculated by successive trials on the $\left(P_{\mathrm{rw}}, V, s\right)$ and $\left(P_{\mathrm{rw}}, V, C_{\mathrm{rw}}\right)$ charts (Fig. 7) until the results are consistent.

\section{Acknowledgments.}

I wish to thank M. Niepceron, of the Institut Aérotechnique de St Cyr for stimulating discussion, and C. Julien, of l'Université du Maine for helping with the translation. 


\section{References}

[1] Whitt, F. R. and Wilson, D. G., Bicycling Science (MIT Press) 1974.

[2] Timoshenko, S. and Young, D. H., Advanced Dynamics (Mac Graw Hill) 1948, p. 234.

[3] Jones, D. E. H., Physics Today, april 1970, p. 34.

[4] Vieren, J. P., The bicycle, La Recherche (1981) 127.

[5] Kirshner, D., Am. J. Phys. 48 (1) (1980) 36-38.

[6] Cazin, M., Cours de Mécanique (Dunod) 1976.

[7] Berthelot, J. M., Cours de Mécanique, I.U.T. Le Mans, 1979.

[8] BANACH, S., Mechanics (Warszawa Wroclaw) 1951, p. 27.
[9] Liesegang, J. and Lee, A. R., Am. J. Phys. 46 (2) (1978) 130-132.

[10] Alexandrov, I. and Lucht, P., Am. J. Phys. 49 (3) (1981) 254-257.

[11] Le cycle (1979), no 52.

[12] Private results of Gitane cycles.

[13] For small $\beta\left(\beta<20^{\circ}\right) S C_{\mathrm{x}}$ keeps constant (le cycle (1982) $\mathrm{n}^{\mathrm{0}}$ 79).

[14] Document Gitane. Stand Gitane. Salon du cycle, Paris, 1979.

[15] Bass, J., Cours de muthématiques (Masson) 1956 p. 869.

[16] Newsweek/June 8, 1981, p. 3. 